\title{
Biological clock vs Social clock conflict in Adolescents
}

\section{Pragya Verma}

Department of Zoology, University of Lucknow, Lucknow-226007 (Uttar Pradesh), India Arjita Yadav

Department of Zoology, University of Lucknow, Lucknow-226007 (Uttar Pradesh), India Sangeeta Rani

Department of Zoology, University of Lucknow, Lucknow-226007 (Uttar Pradesh), India Shalie Malik*

Department of Zoology, University of Lucknow, Lucknow-226007 (Uttar Pradesh), India

*Corresponding author. Email: shellymlk@yahoo.com

\section{Article Info}

https://doi.org/10.31018/ jans.v13i1.2571

Received: February 5, 2021

Revised: March 8, 2021

Accepted: March 12, 2021

\section{How to Cite}

Verma, P. et al. (2021). Biological clock vs Social clock conflict in Adolescents. Journal of Applied and Natural Science, 13(1): 327 - 342. https://doi.org/10.31018/jans.v13i1.2571

\begin{abstract}
Alteration of day and night is one of the essential circadian rhythms that build the phenomenon of sleep/wake in humans and other animals. Daily rhythms impact different individuals differently. Light exposure and an individual's circadian response are two aspects that create diversity in phenotype. These diverse phenotypes are called chronotypes. Chronotype varies over the life history stages. Chronotype is seen as morning type in children, evening type in adolescents, and again reverts back to the morning type in adults and old-aged individuals. It is observed that adolescents being evening types have bedtime later in comparison to children and adults. Adolescent physiology/ body clock does not allow them to sleep early and school routine/social clock does not let them sleep till late. Thus, their night phase is shrunk and sleep hours are reduced, which hinders their daytime functioning, including mental tasks such as cognition, learning and memory-based exercises, and physical tasks such as physical presence during field and athletic events. These days sleep debt is a critical health concern in the adolescent population. The current review focuses on the adolescent sleep-needs and various factors affecting their healthy sleep. This also encompasses the understanding of biological clocks, their misalignment, disrupters, causes and impact. The present study would be helpful in finding out the difference between the biological clock and social clock of the adolescent population, elaborates the need for sleep education and suggests a solution to this alarming problem of sleep debt in teens.
\end{abstract}

Keywords: Adolescent physiology, Biological clock, Circadian rhythms, Clock disruption, Sleep-wake cycle, Social clock

\section{CLOCKS IN HUMAN: AN INTRODUCTION}

All living systems have endogenous, self-sustained biological clocks. Thus biological clocks are ubiquitous. These are inherent timing mechanisms that time the periodicity of various underlying physiological, behavioural and biochemical processes. These endogenous clocks synchronize themselves with external cues such as light, food, society, etc (Van Drunen and Eckel-Mahan, 2021). The ebb and flow of daily life impact individuals differently. This shows that light exposure and an individual's circadian response are two aspects that create diversity in phenotype. These different phenotypes are called chronotypes (Roenneberg, 2015; Kalmbach et al., 2017). This temporal difference of day and night between the two chronotypes could be as large as ten hours
(Roenneberg et al., 2007). Studies indicate that chronotype changes significantly throughout the life span (Randler et al., 2017). Various cross-sectional studies demonstrate that pre-adolescents are morning type, but when they reach their adolescence, they show maximum shifts towards evening types and exhibit the same till 20 years of age; thereafter, they re-shift towards early-type (Roenneberg et al., 2004; Tonetti et al., 2008; Randler et al., 2016). Besides age, there are reports indicating gender-based differences in chronotype (Duffy et al., 2011; Tonetti et al., 2008). Chronotypes are linked to individual's sleep-wake variability, cognition, learning behaviour, and other endogenous clock properties, thereby creating individual temporal niches (Kerkhof, 1985; Karan et al., 2021). As we live in a $24 X 7$ world, keeping aside the body's physiological demands, lead to increased risk 
for health and safety. Maximum work profiles in our social and professional world, irrespective of an individual's chronotype, prefer morning schedules over any other time of the day. In this course, young adults, especially adolescents, are the most vulnerable age group, as most dramatic changes in human life take place in this phase (Susman et al., 2003).

The focus of this review is to bring out the cause and consequence of sleep disturbance in adolescent students. Previous studies have shown that sleep behaviour changes during the adolescent years because of the physiological demand of the body. Teenagers prefer being awake late at night but out of the compulsion of school regime they have to get up early as most of the schools in our country have an early start time (Knutson and Lauderdale, 2009). This latency in going to bed and rising early creates chronic sleep debt in adolescents' life (Hansen et al., 2005). For adolescents, the school timings not only hold the key position in the plan of the daily schedule but are also responsible for their overall health and well-being. By addressing the problem of "early school start time," we can deal with most adolescent health problems. Other societal factors like late-night- screen time, mobile use, internet addiction, workouts, study schedules, exam stress, use of caffeinated drinks at night and many such individual issues also contribute to this problem (McKay et al., 2021). As we are aware, the penalty of the sleep debt is severe; and the payoff is the students' physical and mental health, which compromises their potential for day-time functioning. We have tried to explain the importance of the biological clock and its synchronization with the social clock. We witness a periodic recurrence in the forms of rhythms in almost every phenomenon formulated by nature. We witness these rhythms in every natural phenomenon. Whether it is the alteration of day and night or seasons and tides, everything runs in harmony in nature. Every individual on this planet, from algae to human-being have their internal rhythm. These internal rhythms of an individual are synchronized with the cyclic movements of the environment. Circadian (Circa = about; Diem = a day) rhythms in living beings are regulated by a biological timepiece positioned in the Suprachiasmatic Nuclei (SCN) which lies in the hypothalamus. This clock tunes them with the outer world by accepting various environmental cues (Lockley and Foster, 2012). The body clock sets up the chronotype of a person according to the time preferred by the body's internal demands, which leads to determining major behavioural patterns like- sleepwake cyclicity, emotional balance, introvert-extrovertness, mental-physical performance. The body clock also maintains other crucial biological processes like metabolic activity and physiological demands that include, meal time preference, regulation of blood glu- cose, the release of the required hormone and many such responses (Kozlowska et al., 2020). Suprachiasmatic nucleus is a tiny region of the brain in the hypothalamus responsible for running the circadian body clock and other rhythms associated with the body's peripheral organs (Hilton et al., 2001; Hastings et al., 2003). Circadian rhythmicity is associated with the changes with day-light and day-length. When changes in the light wavelength and light intensity are conspicuous; they are critical for the entrainment of the endogenous circadian timekeeping system in nature. Such non-parametric entrainment underlies a phasedependent (discrete or phasic) sensitivity of the circadian rhythms to daily light-dark cycles. The dark phase is equally important for existence as the light phase of the 24-hour cycle of the day. Dark hours are generally associated with the rest of the sleep.

Sleep, which seems to be very simple, is a very complicated process. It involves several regions of the brain. In addition to it, neurotransmitters and hormonal pathways also play a crucial role. None of these factors can build sleep alone on their own. This complex interplay of different factors makes the process of sleep unique and valuable; therefore, sleep cannot be taken for granted.

In the case of adolescents, it is observed that they are going to bed later in comparison to children and adults. Thus, their night/rest phase is shrunk in comparison to other age groups. Studies have suggested that the duration of sleep keeps on reducing till the age of adolescence but the required duration does not change during teenage years (Crowley et al., 2018). When we step ahead to understand the adolescent circadian clock and sleep behaviour, in light of their physiological demand and the consequences of daily sleep deprivation for attending school in early hours, gives a new angle to address adolescent behaviour (Jain and Khare, 2020). Alongside, Sleep disruption is also one of the root cause of up- and down-regulation of various cognitive and emotional behaviours in individuals (Fig.1). A questionnaire-based study was done on approx.1,50,000 adolescents in which the subjects have shown a diversion towards being evening-type. This change occurred earlier in girls, which matches with the early onset of puberty in them (Tonetti et al., 2008; Randler, 2011). This change again reverts when an individual enters adulthood, which leads to a shift in their chronotype again towards being early-type (Roenneberg et al., 2004). Many studies have shown that the sleep hours during the free days or in the summer break are more in comparison to the work or the school days (Hansen et al., 2005; Jenni et al., 2005). Other studies have also shown that their biological rhythm is not lethargy, which makes them bound to the bed in the morning hours and keeps them wake-up till late in the night. 
One more study based on actigraphic data of sleep showed a trend of development where reduced sleep and delayed onset from child to adolescent are seen (Galland et al., 2018). Another study was conducted to find out sleep debt between biological time and educational time, which has shown the severity of sleep deficit in varied age groups (Foster et al., 2013). Also, survey-based studies from China and Canada indicates that adolescents are prone to chronic sleep debt (Chen et al., 2014; Patte et al., 2017). In today's era, sleep deprivation has reached dangerous levels. This situation is alarming, but fortunately, it is still a controllable affair, which can be solved by keeping the school timings according to the biological clock of adolescents.

Alterations on a chronic basis in sleep pattern during the adolescent period may lead to severe sleeprelated disorders in their later ages, which may harm their health. It is recommended that approx. 9 hours of sleep is required for healthy functioning of the body (Short et al., 2018; Fuligni et al., 2019). Less than 8 hours of sleep on daily basis creates constant sleep debt which has a direct impact on cognitive power, emotional balance and physical health of an individual (Lockley et al., 2004). Studies have also shown that weak immune system, low metabolism, high blood sugar levels, cardiovascular disorders, hypertension, anxiety, stress, obesity and cancerous growth in adolescent are related to the restricted sleep schedule (Foster et al., 2013; De Souza and Hidalgo, 2014; Luyster et al., 2012; Kling and Landgraf, 2021). A study was done to find out the harmful effects of the short duration (5.7 hours per night for one week) of sleep on a healthy body in comparison to those people who were kept under control condition ( 8.5 hours per night for one week); this also revealed that the activity of total 711 different types of genes (responsible for circadian expression) are either upregulated or down-regulated, because of insufficient sleep (Möller-Levet et al., 2013). Based on selfreports of sleep duration made in questionnaire across 40 countries of the world, a systematic review reported that the short duration of sleep adversely affects the mental and physical health of individuals (Chaput et al., 2016). Those adolescents who received recommended amount of sleep were at their best mental health status (Fuligni et al., 2019) whereas, those who slept less than the recommended sleep duration have shown psychological complaints (NorellClarke and Hagquist, 2018). Disturbances in sleep lead to the formation of diseases in the body.

Several findings suggest a relation between sleep debt and obesity (Cappuccio et al., 2008; Chen et al., 2008; Miller et al., 2018), also the evidence-based research from experiments and epidemiology from the past 30 years has connected sleep debt with obesity (Sluggett et al., 2019). Both chronic sleep debt and obesity are issues concerning public health and in light of the researches mentioned earlier, it becomes more noteworthy (Agha and Agha, 2017). Therefore, sleep correction becomes significant in the treatment of obesity (Chaput and Dutil, 2016).

\section{Clock disruption and its effect on adolescents}

Borbély was the first to propose the two-process model of sleep (Borbély, 1982), which explains the role of the circadian system (Process $\mathrm{C}$ ) and homeostatic system (Process S) in maintaining sleep-wake behaviour. The circadian system is responsible for sleep timings irrespective of previous sleep/wake cycles, whereas the homeostatic system is responsible for increasing sleep drive for the amount of wakeful

\section{Impacts of severe sleep disruption}
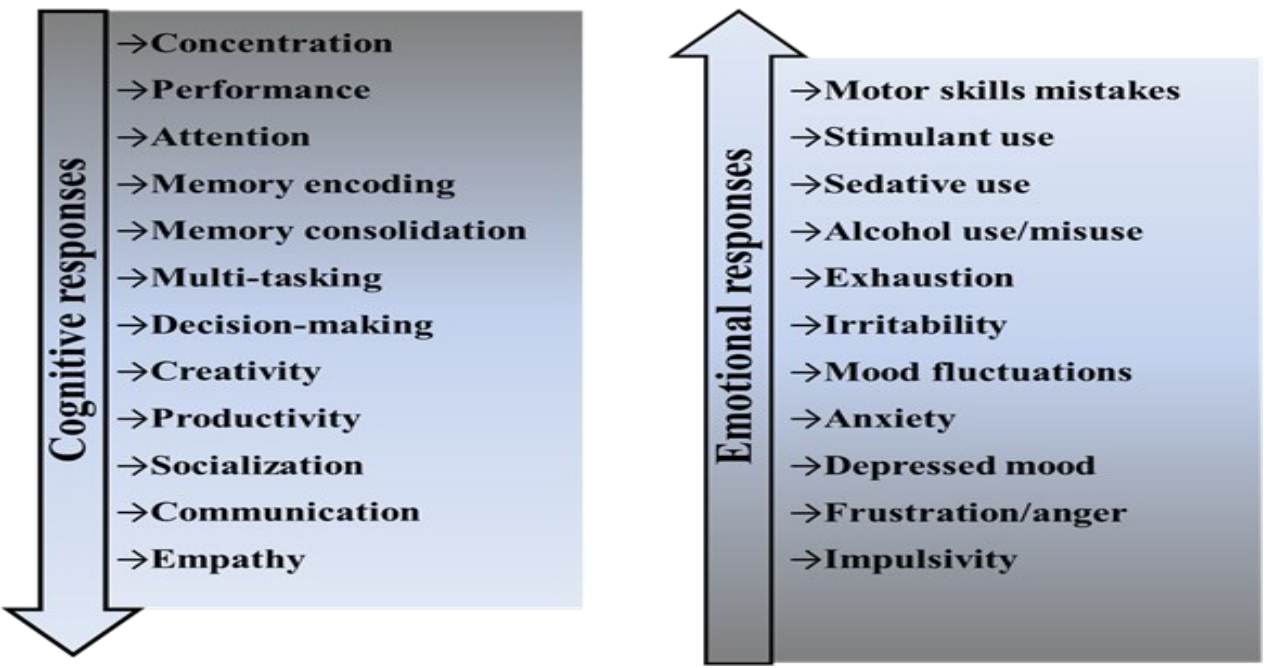

Fig. 1. Impacts of severe sleep disruption on cognitive and emotional responses (redrawn from Wulff et al., 2010). 
period of that individual. If the circadian system or central clock of a living organism is disrupted, it will lead to the misalignment of the entire network of peripheral clocks (Jain and Khare, 2020), which are working in synchrony with each other (Foster et al., 2013). Adolescence is especially an age where delaying in the sleep-wake cycle is notable, and that can be easily understood with the help of the abovementioned two-process model of sleep. Here, with the progress in pubertal age (Carskadon et al., 2004), circadian system shifts to later timings of the day that results in phase-delay in circadian timekeeping system (Hagenauer et al., 2009; Hummer and Lee, 2016). This shift can be seen in their chronotypes (about their sleep-wake times; Roenneberg et al., 2004). Changes in bio-regulation of sleep-wake cyclicity are responsible for sleep burden in adolescents but these alterations in adolescent physiology are not taking place in seclusion (Kozlowska et al., 2020). It is a well-known fact that our body functions efficiently when both biological and social clocks are simulated with each other. In ancient period, both the social and biological time-scales were almost in synchrony because of the less intervention of artificial light at night, technology-based 24x7 lifestyle and unruly academic burden on young people. (Foster and Keitzman, 2014) Difference between social and biological clock creates a misalignment of various rhythms governing smooth body functioning. This desynchrony becomes a potential threat especially to adolescents as they are already undergoing a physiologically turbulent phase (Fig. 2). Therefore, changes in adolescents are an outcome of the mixed effect of the environment in which they live, their daily routine/lifestyle and many other psycho-social factors. There are many factors such as school and exam stress, internet and social media addiction, use of substance and high caffeine drinks which create clock disruption in adolescents.

\section{Clock disrupters}

\section{a) School regime}

Keeping track of time is the basic block on which the theory of the school system, as well as the biological processes, are laid upon, but still, both these sectors have their understanding of time (Peterson, 1996). The meaning of development in the perspective of the school system is evaluated in terms of the number of academic years crossed (based on annual curriculum and daily time-table (Ward, 2021). This trend is more or less the same on the global platform. On the other hand, the biological evaluation of time measurement is done by calculating the development levels. Developments can also be evaluated on a short term basis by considering the response of our body clock in the

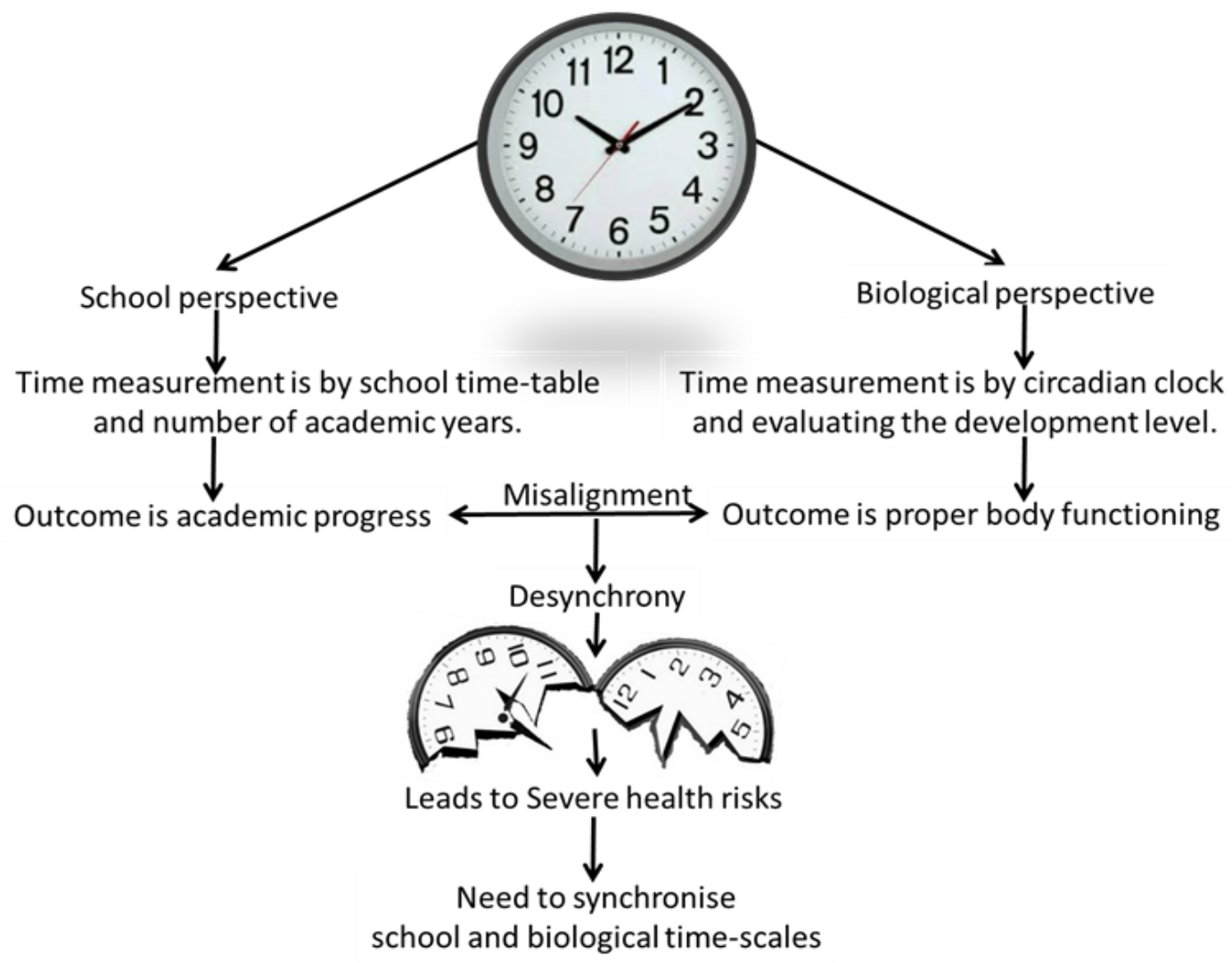

Fig. 2. Importance of time in school and biological perspective and how their misalignment creates a desynchrony which leads to health risks. 
circadian frame. School curriculum and cut-throat competitive exams have compelled students to give extra time to studies from their bed hours(Shochat et al., 2014) and there is no way to compensate nighttime sleep-loss during morning hours as early school start time does not allows them to sleep till late (Chaput et al., 2016). Amid all this school going adolescent's physiological demands are compromised. In addition to it, the majority of schools have morning schedules that force evening type adolescents to wake-up early irrespective of their internal clock. This schedule, on a chronic basis, leads to the circadian misalignment and reduced Sleep (Liu et al., 2021). On a chronic scale, this condition serves as the major cause of "Social jet lag" in adolescents (Wittmann et al., 2006).

\section{School hours}

The school schedule is the main cue around which the routine of adolescents is weaved. There is a need for simulation of the educational system according to adolescent biology. Sleep deprivation among students is not the sole cause behind rescheduling school hours; it is also interlinked with other factors. A few of them are memory-based learning and sleep; circadian variation, chronotype and individual differences sleep hygiene. Good Sleep plays a very important role in building long-term memories (Diekelmann and Born, 2010) and disturbances in it can damage the foundation of the same (Stickgold et al., 2000). Sleep consolidates memory, which is important for mental health and overall well being (Wilhelm et al., 2011). During the adolescent years, it is the student's natural tendency to attain alertness in the later period of the day and remain awake until late at night, making them more likely an evening type individual. Evening type is associated with better attention (Bai et al., 2021). The performance of the adolescents also improves later in the day (Hansen et al., 2005; Hahn et al., 2007; West et al., 2011). A study conducted by Matchock and Mordkoff (2009), showed that at 0800 hours the attention level of individuals belonging to all the chronotypes is significantly low and at 1200, 1600 and 2000 hours their scores almost double up. Another study conducted on the school going students of age group 13-14 years by giving them word-pair test at 1000 \& 1400 hours and then evaluating their performance. It was found that they performed better in the later test (Kelley and Lockley, 2013). There are other related studies also, which provide evidence for similar timein-day effects (Schmidt et al., 2009; Haraszti et al., 2014). According to a study done on students of Spain (12-16 years), late-type students performed significantly poor (Escribano et al., 2012).

\section{Exam stress}

Examination time is considered to be one of the major stress giving times in an individual's life span. An adolescent who is already undergoing so many ups and downs physiologically and socially feel under immense tension when the pressure of achieving good academic grades exceeds. This leads the student to the condition of stress and altered psycho-physical behaviour (Rani, 2017). Exam stress is not just a single term but is associated with sleeplessness, anxiety, time pressure, appetite loss (Putwain, 2008). Exam time stress leads to physical problems (Zunhammer et al., 2013) as well as sleep-related problems. Curtailing on the sleep adversely affects the cognition strength of students and results in poor performance in academics (Curcio et al., 2006; Carskadon, 2011). Certain reports also suggested a difference in examination pressure found in the students studying through science stream and humanities stream. This difference is may be due to Practical classes during school and coaching classes after school (Rani, 2017). Boys are less stressed than girls in their routine (Dewald-Kaufmann et al.2014; Steven, 2016). A study conducted on college-going students shown that the examination stress also results in the suppression of their cardio-respiratory rest function while sleeping at night (Sakakibara et al., 2008). Exam stress is found to be the highest in the examination week, lower than that is seen in the week just before the examination and at least two weeks before the examination started. This kind of pattern is indicative of the role of psychological intervention in the perception of stress (Dewald-Kaufmann et al., 2014).

\section{b) Screen time}

Today our society has turned global, and thus as consequences, there are 24-hour work profiles (Coveney, 2014). In the past ten years, electronic devices have found their space in almost every home on a global level or it can be said that almost every adolescent has access to the technological screen in one form or the other. They have been brought into play in such a way that they entered our bedrooms from the living room. Reports suggest that more than $90 \%$ of adolescent remain with some of the other multimedia devices in their bedrooms when they go to sleep, which hinders the normal sleep timings by delaying it (NSF, 2006). Exposure to light in the evenings will interrupt circadian rhythms by suppressing the release of melatonin. The rhythm of the melatonin hormone is closely linked to sleep and sleep timing (Arendt, 2019). In the evening, exposure to artificial light will alter patterns of sleep and thus changes the sleep duration (Touitou and Point, 2020). Besides, electronic devices emit light with a short wavelength (i.e. blue light). In this 
range, the circadian system is alarmingly sensitive to light (Cajochen et al., 2011; Bertani et al., 2021). Excessive use of these gadgets at bedtime has significant detrimental effects on sleep duration and quality (Hysing et al., 2015). 24/7 access to the technology, especially mobile and laptop screens (which emits blue wavelength) have played a significant role in increasing alertness and delayed sleep onset (Rüger et al., 2012). The weekday-weekend gap in getting-up time is larger in adolescents but in adult evening types, which shows circadian misalignment (Adan, 1994; Broms et al., 2011).

A widely acclaimed review of 36 studies published in 2010 showed that excessive media use in children and adolescents is associated with delayed bedtime and shorter sleep periods (Cain and Gradiser, 2010; Kokka et al., 2021). A broad US-based survey examined whether the sleep pattern persisted between 2009 and 2015 and the factors that could contribute to its decrease. By 2015 , more than $40 \%$ of teenagers regularly slept less than 7 hours a night, $16-17 \%$ more often than in 2009. During the analysis period, time for usage of digital media screens increased (including mobile devices, social media and reading of online news) and also the chances for a shorter period of sleep increased. Notably, during these years, there has been no rise in other behaviours which could be suggested to interfere with sleep (TV, pay job, homework; Twenge et al., 2017).

The cross-sectional data from the Millennium Cohort Study in the UK were used in another large-scale research (Scott et al., 2019). The authors analyzed social media usage by 11,872 adolescents aged between 13 to 15 years and sleep results associations using 2014 data. The use of social media was measured using one item: the time spent on social media on a typical weekday. Larger use of social media has been related to weaker sleep after covariate control. Specifically, highly addictive social media users who used social networks more than 5 hours a day (20.8\%) were more likely to record a late sleep onset during the school week, compared to users who used social media 1 to 3 hours a day (31.6\%). Handys (mobiles) are omnipresent and a part of daily life. In fact, they are seen as an important tool for social interaction by young people. A longitudinal study evaluated the impact of mobile phone use in Western Australia for over four years from 2010 to 2013. Individuals were asked what time text messages or telephone calls were typically sent or received and whether they continued after the lights are off. Over these years, the use of cell phones at night has increased, equally leading to corresponding increases in bad sleep practices (Vernon et al., 2018).

Studies have mostly used the survey-based data and correlation statistics, although a recent experimental study requested teenagers to avoid using their mobiles one hour before their normal bedtime and also to complete a sleep diary along with. Results revealed that during the intervention week, teenagers avoided using their mobile 80 minutes before, put their lights off 17 minutes before, and sleep lasted 21 minutes longer than school-night (Bartel et al., 2019). Along with circadian misalignment, such individuals also tend towards psychological dysregulation, addiction to alcohol abuse and involvement in substance use (Gau et al., 2007, Pieters et al., 2010; Saxvig et al., 2012, Stolarski et al., 2021). Survey also shows that the students have given data for a relation between sleep-related issues and alcohol consumption along with substance use (Lund et al., 2010; Pieters et al., 2010).

\section{c) Caffeine}

Caffeine is the commonest consumed psychoactive substance. It blocks adenosine receptors (Roehrs and Roth, 2008). Caffeine is seen as a problem for sleep because adenosine is a neurochemical substance whose level increases wakefulness in the brain (FavrodCoune and Broers, 2021); adenosine is suggested to stimulate sleep and play a role in homeostasis in sleep (Basheer et al., 2004). Afternoon or evening caffeine consumption can be an issue of concern as the half-life of single-dose takes between 3-7 hours and may hinder the process of falling asleep (Roehrs and Roth, 2008). In recent years, energy drinks have received publicity; in particular, the youth consumption trend has increased. Caffeine is a major component of energy drinks It gives $113-200 \mathrm{mg}$ energy shot with $70-200 \mathrm{mg}$ presence in a 16-ounce drink (NCCIH, 2018). More than two-thirds of the adolescents were registered to use energy beverages in the UK (DHSC, 2018), and one-third in the USA (NCCIH, 2018). Energy drinks have been noted to gain popularity among adolescents in recent years, as it increases the alertness and helps battle the sleepiness (Bryant and Wolfson, 2010, Yasuma et al., 2021).

Factors other than the above-listed causes are also responsible for creating motivation for the later sleep timings in adolescents.

\section{Impacts of clock disrupters \\ a) Metabolic Imbalances}

Many past studies revealed how human physiology and a few disorders are directly linked with circadian rhythms (Schernhammer et al., 2003, Gale et al., 2011, Martino et al., 2008, Wulff et al., 2012 ). Metabolic homeostasis, specifically in adipose tissue is an important element that is responsible for energy metabolism. Adipose tissue is the reservoir that fulfils the major energy demands of the body whereas, brown 


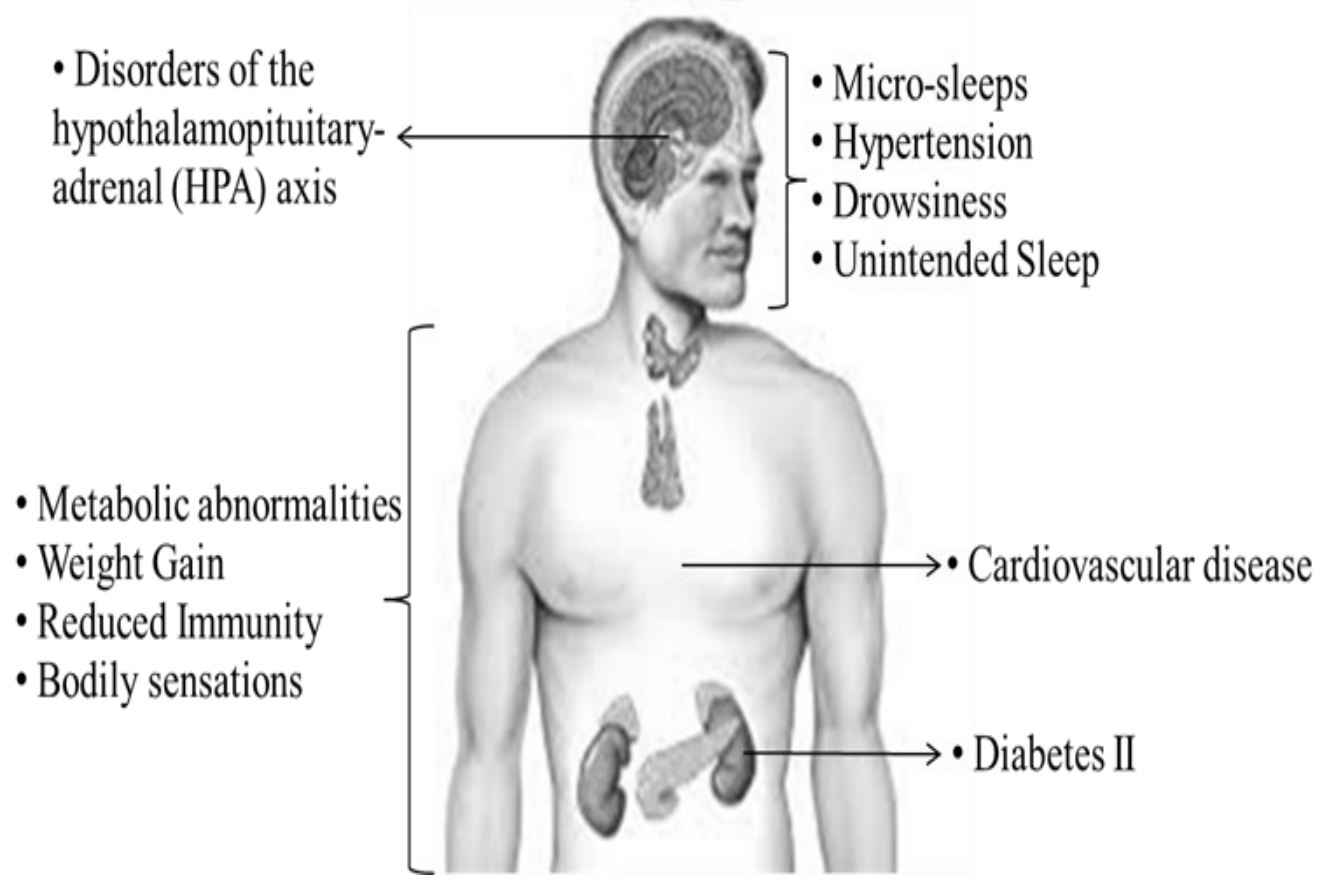

Fig. 3. Effects of sleep disruption on physiological responses (redrawn from Foster and Wulff, 2005).

adipose tissue accumulates lipids for adaptive thermogenesis caused by cold weather. Adipose tissues secrete multiple hormones, cytokines and metabolites that control the signal for appetite in CNS and metabolism in peripheral tissues (Choe et al., 2016), e.g. leptin has unique hypothalamic receptors and is released from the principal adipocytes. Leptin increases thyroid hormone levels and stimulates the sympathetic central nervous system, which leads to increased formation of the uncoupling protein which leads to greater use of energy (Con et al., 2017). Leptin hormone release follows circadian rhythmicity, where the night is the time when a maximum of serum leptin level is recorded (Tsujino and Sakurai, 2012). Now,

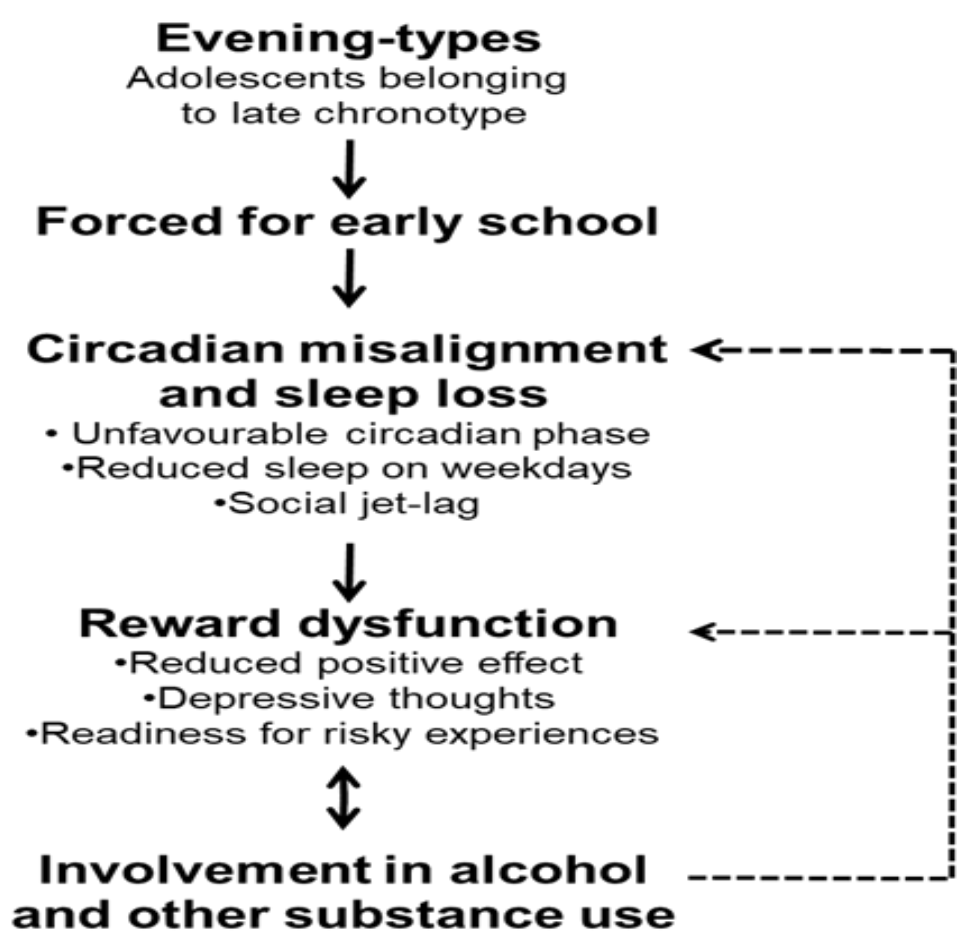

Fig. 4. A conceptual map showing circadian misalignment leading to the alcohol abuse and substance use in adolescents (based on Hasler and Clark, 2013; Hasler et al., 2015). 
disturbance in the night time sleep may lead to circadian misalignment that can indirectly affect the whole chain of the secretion of leptin, process of thermogenesis and homeostasis of energy. On the opposite, certain hypothalamic hormones display more night activity, e.g., growth hormone peaks between 2:00 to 4:00 a.m in the night. Imagine if the adolescent has a disturbance in nighttime sleep, then it will adversely impact the growth of that individual. Therefore, particular attention must be given to children's sleep patterns also (Sato and Ida, 2017).

Chrono-disruption is the misalignment of peripheral clocks with the central clock (Garaulet et al., 2010), which leads to some serious diseases (Ahmad, 2020). Majority of diseases are lifestyle disorders such as cardiovascular diseases, depression, obesity and metabolism (Garaulet et al., 2014) (Fig. 3). The circadian clock plays a significant role in the homeostasis of energy and metabolism. Circadian therapies thus, focused on rhythm, diet and exercise that have been introduced in recent times to maintain metabolism, which is referred to as 'chrono-pharmacology,' 'chrono -nutrition' and 'chrono-exercise,' respectively (Azmi et al., 2020). Factors such as shift work, disturbed sleep, insomnia, that are capable of triggering circadian rhythm disruption need assessment particularly in people with metabolic disorders, such as obesity (Garcez et al., 2021). Plans to schedule workout and meals according to their normal biological rhythms can boost treatment efficiency in these patients.

\section{b) Psychological disorders}

There is ample literature available that demonstrates the between mood, light, and circadian rhythms (Bedrosian and Nelson, 2017; Arns et al., 2021). Light at night can be considered as one of the most prominent biological and behavioural clock disrupters that leads to psychological imbalances. Many mood disorders are either characterized by sleep and circadian rhythm disturbance or by an abnormal light-dark cycle. Seasonal affective disorder (SAD) is a recurring depressive disorder in which a patient's mood swings between dysthymia (in winters) and euthymia (in summers). Other disorders such as Shift Work Disorder, Severe Depression, Bipolar Disorder, PTS, Common Anxiety are directly linked with irregular sleep pattern (APA, 2013). However, the essence of the relationship between circadian rhythm dysfunction and psychopathology is poorly known (Jones and Benca, 2015). However, rodent studies have shown that even experimentally induced circadian rhythm disorders can induce changes in healthy animals. If resynchronization of circadian rhythm in patients is targeted, then symptoms of mood disorders can be improved. Although circadian disturbances may not be the only cause of mood diseases, they may cause or intensify symptoms in people with a tendency of mood-related disorders.

\section{c) Alcohol, substance abuse and reward dysfunction}

According to the reports, approximately $31 \%$ of college-going students live their life in circumstances favourable for an individual to get into alcohol abuse, which is likely to be increased by $6 \%$ (Chawla et al., 2007). The tendency for consuming alcohol and nicotine is more in evening-type individuals when compared with morning types.

Eveningness shows its relation with the rewardrelated brain dysfunction, which comprises depression, reduction in reward response and increased need for sensation seeking (Hasler et al., 2010; Tonetti et al., 2010) (Fig. 4). Brain areas involved in the reward processing also show a changed activity, especially in evening types (Hasler et al., 2012). Adolescents who are comparatively insensitive towards the reward may develop a tendency to seek reward through alcohol abuse (Spear, 2000). Two studies conducted on adolescents report that the larger the difference between the sleep of weekdays and weekend, which points towards circadian misalignment, leads to the increase in risk-taking behaviour (O'Brien and Mindell, 2005; Pasch et al., 2010). Circadian misalignment generally goes hand in hand with sleep loss and sleep disturbance, which greatly impacts the increased homeostatic drive which in turn is responsible for the involvement in reward dysfunction, risktaking, alcohol abuse and substance use (Tamura et al., 2021).

\section{d) Road accidents}

Road accidents nowadays have increased in multiple folds in comparison to the later in a decade. A noticeable fact is that adolescent drivers have also increased in number. It is seen that the adolescent drivers are more prone to the morning accident in comparison to the older ones (Danner and Phillips, 2008; Czeisler, 2009; Vorona et al., 2011). It is a fact that sleepiness and tiredness due to incomplete sleep have a direct link with motor accidents (Garbarino, 2001; Connor et al., 2001, Connor, 2002; Philip et al., 2002). These accidents are the clear case of functional inactivity due to the wake-up schedule which is out of the circadian phase. Pack et al. (1995) is accredited for making this on the record and universally accepted that individuals with sleepiness but without any known sleep-related disorder could be the reason for road accidents. Pack's team analyzed the reports of the crashes in North Carolina in the year 1990 and 1992. The reports revealed the review of those crashes in which the driver was thought to have slept while driving the vehicle. Out of these $55 \%$ of crashes 
happed with individuals who were at the age of 25 or below (Lowden et al., 2009; Akerstedt and Kecklund, 2001). Among teenagers the problem of being drowsy while driving is a major issue of concern (Pizza et al., 2010; Taylor and Bramoweth, 2010). According to some studies done on high school grade students (having a driving license), where $11 \%$ of the total went into crash while driving automobiles due to sleepiness as its main cause. Also, $40 \%$ have registered that they feel sleepy while driving, while two-third of them were the sufferer of day-time sleepiness and one-fifth had poor sleep quality (Sagaspe et al., 2007).

These studies are suggestive of the need for the counter strategy to deal with the problem of road accidents due to sleep deficit in adolescents (Oyegbile, 2020). Setting up school timings according to the biological clock of adolescents will address the majority of this problem and rest can be solved by advising the youth not to drive when drowsy and saying a 'No' to drink and drive. Planned napping could be another alternative solution for the same (Smith-Coggins et al., 2006).

\section{Sleep education is a must}

Sleep education is an instrument to deal with the psychosocial and lifestyle factors that can improve the lives of individuals. Adolescents may take part in behaviour that does not encourage them to sleep, although the use of good practices in 'sleep hygiene,' such as regular sleep and a sleep-friendly routine, may help (Sari and Annisa, 2021). Schools should provide an atmosphere where teens can get information about sleep, just like other valuable information about health and hygiene in their classroom. Sleep education programme focuses on increasing teenagers' consciousness about the significance of sleep and enhancing sleep health. Reviews of these programs' effectiveness indicate that awareness of sleep hygiene has significantly improved while sleep behaviour improvement is still limited (Froy, 2012; Tahara and Shibata, 2013; Oike, 2017).

\section{A suggestive solution}

Studies in the field of circadian biology and sleep medicine influence the education system directly (Azmi, 2020). There is a need for proper sleep hygiene (Sari and Annisa, 2021). The USA addressed this problem by shifting the schools toward later timings, where middle and high schools were recommended to begin not before 8.30 a.m. (Brown et al., 2002). This delaying aimed to minimize insufficient sleep and social jetlag, thus reducing the mismatch in adolescents' social and biological clocks. Authorities and policymakers must be aware of the risks of sleep debt and they should consider the late school hours over the early hours to make adolescents, healthy learners (Kelley and Lee, 2014; Sari and Annisa, 2021). Along with the general approach towards delaying school hours, there should be an understanding of the effect of chronotype on an individual's behaviour (Karan et al., 2021). This not only will save the health of students but also will benefit the young teachers.

Our government is making efforts to create a healthy environment for school going students (Stolarski et al., 2021). Later start of school may solve the purpose to a great extent (Jacob and Rockoff, 2012; Kirby et al., 2011). Our knowledge of the need for sleep is enhancing on a daily basis. Still, there is a need for spreading awareness regarding the importance of sleep among common people (Chauvette et al., 2012; Grosmark et al., 2012). In other countries, change has already started to appear; even the awareness regarding this is being spread by some agencies like the National Sleep Foundation and Start School Later campaign. Shifting school timings to later hours is a practical approach because misalignment of the sleep schedule with the school timing, if carried over for a prolonged period, will result in regularly persistent and irrefutable sleep-debt. Adolescents already undergo tremendous developmental changes on the level of their brain and body, and in addition to it, if they will not get proper sleep to rejuvenate, then this chronic sleep debt may hamper their emotional, mental, physiological and metabolic well-being on a serious note (Hansen et al., 2005; Giedd, 2009; Giedd et al., 2012; Sawyer et al., 2012; Sørensen et al., 2012; Foster et al., 2013; Ahmad, 2020). Alignment of the biological and school clock will help adolescents in improving their health, along with the better academic performance that too in a relatively less stressed atmosphere (Ward, 2021). Also, this initiative will not require any new methodology for teaching-learning or any kind of expenditure. This will reduce health risk without using any medication or treatment (Liu et al., 2021). There is considerable data in support of adolescent population being under the disadvantages of unsuitable school hours. Keeping the timing of the schools in sync with the adolescent biological clock is the call of the hour, which is both practical and essential. It also reflects that a better environment can be created for the adolescents, in the light of good transdisciplinary research data available on sleep science, neurobiology and educational research (Gabrieli, 2009; Meltzoff et al., 2009).

\section{Conclusion}

Today's teens face obstacles such as completion of home-work in late-night study schedules, social media activity, and their own physiology itself pose a limit to their daily amount of sleep. The impact of social influ- 
ences is doubtless profound, with an important role in the proliferation and habitual use of electronic media. Further study is required to determine the mechanistic course of effect of the electronic media on sleep. Chronic sleep debt is a critical health concern because of the important role of sleep in different aspects of our lives. However, it must be remembered that other sleep and circadian variables are often explored as potentially influential factors such as sleep quality, sleep duration, regularity and sleep onset. Encouragingly, movements to recognize and incorporate strategies for improvement of sleep for adolescents' well-being have gained traction. The knowledge about sleep education needs to be spread to educate the adolescent and youths and empower them to change jeopardizing behaviour related to sleep needs.

\section{ACKNOWLEDGEMENTS}

This work was supported by the ICMR fellowship programme under grant (SRF/9/2019/SBHSR; Fellowship ID 2019-5190). Also, Mr. Ramji Dubey and Ms. Anupama Yadav are highly acknowledged for their valuable suggestions.

\section{Conflict of interest}

The authors declare that they have no conflict of interest.

\section{REFERENCES}

1. Adan, A. (1994). Chronotype and personality factors in the daily consumption of alcohol and psychostimulants. Addiction, 89(4), 455-462. DOI: 10.1111/j.1360-0443.19 94.tb00926.x.

2. Agha, M, and Agha, R. (2017). The rising prevalence of obesity: part A: impact on public health. Int. J. Surg. Oncology 2: e17. DOI: 10.1097/IJ9.000000000000 0017.

3. AHMAD, Mahadir. (2020). The Effects of Circadian Rhythm Disruption towards Metabolic Stress and Mental Health: A Review. Jurnal Sains Kesihatan Malaysia (Malaysian Journal of Health Sciences), 18(1), 1. DOI: 10.17576/JSKM-2020-1801-07

4. Akerstedt, T. and Kecklund, G. (2001). Age, gender and early morning highway accidents. Journal of Sleep Research, 10(2), 105-110. DOI: 10.1046/j.1365-2869.20 01.00248.x

5. APA (2013). Diagnostic and Statistical Manual of Mental Disorders. American Psychiatric Association. 5th edn American Psychiatric Publishing, Arlington, VA, USA.

6. Arendt J. (2019). Melatonin: Countering Chaotic Time Cues. Frontiers in Endocrinology, 10, 391. DOI: 10.33 89/fendo.2019.00391

7. Arns, M., Kooij, J., and Coogan, A. N. (2021). Review: Identification and Management of Circadian Rhythm Sleep Disorders as a Transdiagnostic Feature in Child and Adolescent Psychiatry. Journal of the American Academy of Child and Adolescent Psychiatry, S0890-
8567(21), 00059-9. DOI: 10.1016/j.jaac.2020.12.035.

8. Bai, S., Karan, M., Gonzales, N., and Fuligni, A. (2021). A daily diary study of sleep chronotype among Mexicanorigin adolescents and parents: Implications for adolescent behavioral health. Development and Psychopathology, 33(1), 313-322. DOI:10.1017/S0954579419001780.

9. Bartel, K., Scheeren, R., and Gradisar, M. (2019). Altering Adolescents' Pre-Bedtime Phone Use to Achieve Better Sleep Health. Health Communication, 34(4): 456462. DOI: 10.1080/10410236.2017.1422099.

10. Basheer, R., Strecker, R. E., Thakkar, M. M., and McCarley, R. W. (2004). Adenosine and sleep-wake regulation. Progress in Neurobiology, 73(6), 379-396. DOI:10.1016/j.pneurobio. 2004.06.004.

11. Bedrosian, T. A., and Nelson, R. J. (2017). Timing of light exposure affects mood and brain circuits. Translational Psychiatry, 7(1), e1017. DOI: 10.10 38/tp.2016.262

12. Bertani, D. E., De Novellis, A., Farina, R., Latella, E., Meloni, M., Scala, C., Valeo, L., Galeazzi, G. M., and Ferrari, S. (2021). "Shedding Light on Light": A Review on the Effects on Mental Health of Exposure to Optical Radiation. International Journal of Environmental research and Public Health, 18(4), 1670. DOI:10.3390/ ijerph18041670

13. Borbély A. A. (1982). A two process model of sleep regulation. Human Neurobiology 1(3), 195-204.

14. Broms, U., Kaprio, J., Hublin, C., Partinen, M., Madden, P. A., and Koskenvuo, M. (2011). Evening types are more often current smokers and nicotine-dependent-a study of Finnish adult twins. Addiction (Abingdon, England), 106(1), 170-177. DOI: 10.1111/j.1360-0443.20 10.03112.x

15. Brown, S. A., Zumbrunn, G., Fleury-Olela, F., Preitner, N., and Schibler, U. (2002). Rhythms of mammalian body temperature can sustain peripheral circadian clocks. Current biology: CB, 12(18), 1574-1583. DOI: 10.1016/s0960-9822(02)01145-4

16. Wulff, K., Dijk, D. J., Middleton, B., Foster, R. G., and Joyce, E. M. (2012). Sleep and circadian rhythm disruption in schizophrenia. The British Journal of Psychiatry, 200(4), 308-316.

17. Cain, N., and Gradisar, M. (2010). Electronic media use and sleep in school-aged children and adolescents: $A$ review. Sleep Medicine, 11(8), 735-742. DOI: 10.1016/ j.sleep.2010.02.006.

18. Cajochen, C., Frey, S., Anders, D., Späti, J., Bues, M., Pross, A., Mager, R., Wirz-Justice, A., and Stefani, O. (2011). Evening exposure to a light-emitting diodes (LED)-backlit computer screen affects circadian physiology and cognitive performance. Journal of applied physiology (Bethesda, Md. : 1985), 110(5), 1432-1438. DOI:10.1152/japplphysiol.00165.2011.

19. Cappuccio, F. P., Taggart, F. M., Kandala, N. B., Currie, A., Peile, E., Stranges, S., and Miller, M. A. (2008). Meta -analysis of short sleep duration and obesity in children and adults. Sleep, 31(5), 619-626. DOI:10.1093/slee $\mathrm{p} / 31.5 .619$.

20. Carskadon, M. A., Acebo, C., and Jenni, O. G. (2004). Regulation of adolescent sleep: implications for behavior. Annals of the New York Academy of Sciences, 1021, 276-291. DOI:10.1196/annals. 1308.032. 
21. Carskadon, M. A. (2011). Sleep in adolescents: the perfect storm. Pediatric Clinics, 58(3), 637-647.

22. Chaput, J. P., Gray, C. E., Poitras, V. J., Carson, V., Gruber, R., Olds, T., Weiss, S. K., Connor Gorber, S., Kho, M. E., Sampson, M., Belanger, K., Eryuzlu, S., Callender, L., and Tremblay, M. S. (2016). Systematic review of the relationships between sleep duration and health indicators in school-aged children and youth. Applied Physiology, Nutrition, and Metabolism = Physiologie Appliquee, Nutrition et Metabolism, 41(6 Suppl 3), 266-282. DOI: 10.1139/apnm-2015-0627.

23. Chaput, J. P., and Dutil, C. (2016). Lack of sleep as a contributor to obesity in adolescents: impacts on eating and activity behaviors. The international Journal of Behavioral Nutrition and Physical Activity, 13(1), 103. DOI:10.1186/s12966-016-0428-0.

24. Chauvette, S., Seigneur, J., and Timofeev, I. (2012) Sleep oscillations in the thalamocortical system induce long-term neuronal plasticity. Neuron, 75(6),1105-1113. DOI:10.1016/j.neuron.2012.08.034.

25. Chawla, N., Neighbors, C., Lewis, M. A., Lee, C. M., and Larimer, M. E. (2007). Attitudes and perceived approval of drinking as mediators of the relationship between the importance of religion and alcohol use. Journal of Studies on Alcohol and Drugs, 68(3), 410-418. DOI: 10.15288/jsad.2007.68.410.

26. Chen, X., Beydoun, M. A., and Wang, Y. (2008). Is sleep duration associated with childhood obesity? A systematic review and meta-analysis. Obesity (Silver Spring, Md.) 16(2), 265-274. DOI: 10.1038/oby.2007.63.

27. Chen, T., Wu, Z., Shen, Z., Zhang, J., Shen, X., and Li, S. (2014). Sleep duration in Chinese adolescents: biological, environmental, and behavioral predictors. Sleep medicine, 15(11), 1345-1353. DOI:10.1016/j.sleep.20 14.05.018

28. Choe, S. S., Huh, J. Y., Hwang, I. J., Kim, J. I., and Kim, J. B. (2016). Adipose Tissue Remodeling: Its Role in Energy Metabolism and Metabolic Disorders. Frontiers in endocrinology, 7, 30. DOI: 10.3389/ fendo.2016.00030.

29. Çon, M., Dalgın, D., Cenesiz, M., and Cenesiz, S. (2017). Leptin ve adiponektinin enerji ve egzersiz ilişkisi. Spor ve Performans Araştırmaları Dergisi, 154-154. DOI:10.17155/omuspd.305531.

30. Connor, H., Dewson, S., Tyers, C., Eccles, J., Regan, J., and Aston, J. (2001). Social class and higher education: issues affecting decisions on participation by lower social class groups. Research Report 27. https:// www.researchgate.net/publication/2683 66216_Socia I _Class_and_High er_Education_Issues_Affe cting_Dec isions_on_Participation_by_Lower_Social_Class_Groups

31. Connor, J. (2002). Driver sleepiness and risk of serious injury to car occupants: population based case control study. BMJ, 324(7346), 1125-1125. DOI:10.1136/ bmj.324.7346.1125

32. Coveney, C. M. (2014). Managing sleep and wakefulness in a 24-hour world. Sociology of Health and IIIness, 36(1), 123-136. DOI:10.1111/1467-9566.12046

33. Crowley, S. J., Wolfson, A. R., Tarokh, L., and Carskadon, M. A. (2018). An update on adolescent sleep: New evidence informing the perfect storm model. Journal of adolescence, 67, 55-65. DOI:10.1016/j.ad olescence. 2018.06.001

34. Curcio, G., Ferrara, M. and Gennaro, L. De. (2006). Sleep Loss, Learning Capacity and Academic Performance. Sleep Medicine Review, 10(5), 323337. DOI: 10.1016/j.smrv.2005.11.001

35. Czeisler, C. A. (2009). Medical and Genetic Differences in the Adverse Impact of Sleep Loss on Performance: Ethical Considerations for the Medical Profession. Transactions of the American Clinical and Climatological Association, 120, 249-285.

36. Danner, F. and Phillips, B. (2008). Adolescent Sleep, School Start Times, and Teen Motor Vehicle Crashes. Journal of Clinical Sleep Medicine, 4(6), 533-5.

37. De Souza, C. M. and Hidalgo, M. P. L. (2014). Midpoint of Sleep on School Days Is Associated with Depression Among Adolescents. Chronobiology International, 31 (2), 199-205. DOI:10.3109/07420528.2013.838575

38. DHSC (2018). Consultation on proposal to end the sale of energy drinks to children. See Impact Assessment. https://www.gov.uk/government/consultations/ending-the -sale-of-energy-drinks-to-children

39. Dewald-Kaufmann, J. F., Oort, F. J., and Meijer, A. M. (2014). The effects of sleep extension and sleep hygiene advice on sleep and depressive symptoms in adolescents: a randomized controlled trial. Journal of Child Psychology and Psychiatry, 55(3), 273-283. DOI:10.111 1/jcpp.12157

40. Diekelmann, S. and Born, J. (2010). The Memory Function of Sleep. Nature Reviews, Neuroscience, 11(2), 114 -126. DOI:10.1038/nrn2762

41. Duffy, J. F., Cain, S. W., Chang, A. M., Phillips, A. J. K., Münch, M. Y., Gronfier, C. and Wyatt, J. K., et al. (2011). Sex Difference in the Near-24-Hour Intrinsic Period of the Human Circadian Timing System. Proceeding of the National Association of Sciences of the USA, 108(S3), 15602-15608. DOI:10.1073/pnas.1010 666108

42. Escribano, C., Diaz-Morales, J. F., Delgado, P., and Collado, M. J. (2012). Morningness/ Eveningness and School Performance Among Spanish Adolescents: Further Evidence. Learning and Individual Differences, 22 (3), 409-413. DOI:10.1016/j.lindif.2011.12.008.

43. Favrod-Coune T., and Broers B. (2021). Addiction to Caffeine and Other Xanthines. In: el-Guebaly N., Carrà G., Galanter M., Baldacchino A.M. (eds) Textbook of Addiction Treatment. Springer, Cham. DOI:/10.1007/978 -3-030-36391-8_16.

44. Foster, R., Wulff, K. (2005). The rhythm of rest and excess. Nat Rev Neurosci., 6, 407-414. DOI:10.1038/ nrn1670.

45. Foster, R. G., Peirson, S. N., Wulff, K. E., Winnebeck, Vetter, C. and Roenneberg, T. (2013). Sleep and Circadian Rhythm Disruption in Social Jetlag and Mental IIIness. Progress in Molecular Biology and Translational Science 119: 325-346. DOI:10.1016/B978-0-12-3969712.00011-7.

46. Foster, R.G. and Kreitzman, L. (2014). The rhythms of life: what your body clock means to you!. Experimental Physiology, 99(4), 599-606. DOI:10.1113/expphysiol.20 12.071118 .

47. Froy O. (2012). Circadian rhythms and obesity in mammals. ISRN Obesity, 2012, 437198. DOI:10.5402/20 
$12 / 437198$

48. Fuligni, A. J., Bai, S., Krull, J. L., and Gonzales, N. A. (2019). Individual Differences in Optimum Sleep for Daily Mood During Adolescence. Journal of clinical child and adolescent psychology : the official Journal for the Society of Clinical Child and Adolescent Psychology, American Psychological Association, Division 53, 48(3), 469-479. DOI:10.1080/15374416.2017. 1357126.

49. Gabrieli J. D. (2009). Dyslexia: a new synergy between education and cognitive neuroscience. Science (New York, N.Y.), 325(5938), 280-283. DOI:10.1126/sci ence.1171999

50. Gale, J. E., Cox, H. I., Qian, J., Block, G. D., Colwell, C. S., and Matveyenko, A. V. (2011). Disruption of circadian rhythms accelerates development of diabetes through pancreatic beta-cell loss and dysfunction. Journal of BiologicalRrhythms, 26(5), 423-433. DOI:1 0.1177/0748730411416341.

51. Galland, B. C., Short, M. A., Terrill, P., Rigney, G., Haszard, J. J., Coussens, S., Foster-Owens, M., and Biggs, S. N. (2018). Establishing normal values for pediatric nighttime sleep measured by actigraphy: a systematic review and meta-analysis. Sleep, 41(4), DOI:1 0.1093/sleep/zsy017.

52. Garaulet, M., and Gómez-Abellán, P. (2014). Timing of food intake and obesity: a novel association. Physiology and behavior, 134, 44-50. DOI:10.1016/j.physbeh.201 4.01.001

53. Garaulet, M., Ordovás, J. M., and Madrid, J. A. (2010). The chronobiology, etiology and pathophysiology of obesity. International Journal of Obesity (2005), 34(12), 1667-1683. DOI:10.1038/ijo.2010.118.

54. Garbarino, J. (2001). An ecological perspective on the effects of violence on children. Journal of Community Psychology, 29(3), 361-378. DOI:10.1002/jcop.1022

55. Garcez, M. R., de Castro, M. A., César, C. L. G., Goldbaum, M., and Fisberg, R. M. (2021). A chrononutrition perspective of diet quality and eating behaviors of Brazilian adolescents in associated with sleep duration. Chronobiology International, 0(0), 1-13. DOI:10.1080/07420528.2020.1851704

56. Gau, S. S., Shang, C. Y., Merikangas, K. R., Chiu, Y. N., Soong, W. T., and Cheng, A. T. (2007). Association between morningness-eveningness and behavioral/ emotional problems among adolescents. Journal of Biological Rhythms, 22(3), 268-274. DOI:10.1177/074 8730406298447.

57. Giedd, J. N. (2009). Linking Adolescent Sleep, Brain Maturation, and Behavior. Journal of Adolescent Health, 45(4), 319-320. DOI:10.1016/j.jadohealth.2009.07.007.

58. Giedd, J. N., Raznahan, A. K., Mills, L. and Lenroot, R. K. (2012). Review: Magnetic Resonance Imaging of Male/Female Differences in Human Adolescent Brain Anatomy. Biology of Sex Differences, 3(1), 19. DOI: 10.1186/2042-6410-3-19.

59. Grosmark, A. D., Mizuseki, K. E., Pastalkova, Diba, K. and Buzsáki, G. (2012). REM Sleep Reorganizes Hippocampal Excitability. Neuron, 75(6), 1001-1007. DOI:10. 1016/j.neuron.2012.08.015.

60. Hagenauer, M. H., Perryman, J. I., Lee, T. M., and Carskadon, M. A. (2009). Adolescent changes in the homeostatic and circadian regulation of sleep. Developmental Neuroscience, 31(4), 276-284. DOI:10.1159/000216538.

61. Hahn, C., Cowell, J. M., Wiprzycka, U. J., Goldstein, D., Ralph, M., Hasher, L. and Zelazo, P. D. (2007). Circadian Rhythms in Executive Function During the Transition to Adolescence: The Effect of Synchrony Between Chronotype and Time of Day. Cognitive Neuropsychology, 24 (7): 755-789. DOI: 10.1111/j.1467-7687.2012.01137.x.

62. Hansen, M., Janssen, I., Schiff, A., Zee, P. C. and Dubocovich, M. L. (2005). The Impact of School Daily Schedule on Adolescent Sleep. Pediatrics, 115(6), 1555-1561. DOI: 10.1542/peds.2004-1649.

63. Haraszti, R. Á., Ella, K., Gyöngyösi, N., Roenneberg, T. and Káldi, K. (2014). Social Jetlag Negatively Correlates with Academic Performance in Undergraduates. Chronobiology International, 31(5), 603-612.

64. Hasler, B. P., Allen, J. J., Sbarra, D. A., Bootzin, R. R., and Bernert, R. A. (2010). Morningness-eveningness and depression: preliminary evidence for the role of the behavioral activation system and positive affect. Psychiatry Research, 176 (2-3), 166-173. DOI:10.1016/j.psychres.2009.06.006.

65. Hasler, B. P., Dahl, R. E., Holm, S. M., Jakubcak, J. L., Ryan, N. D., Silk, J. S., Phillips, M. L., and Forbes, E. E. (2012). Weekend-weekday advances in sleep timing are associated with altered reward-related brain function in healthy adolescents. Biological Psychology, 91(3), 334341. DOI:10.1016/j.biopsycho.2012.08.008.

66. Hasler, B. P., and Clark, D. B. (2013). Circadian misalignment, reward-related brain function, and adolescent alcohol involvement. Alcoholism, Clinical and Experimental research, 37(4), 558-565. DOI: 10.1111/ acer.12003.

67. Hasler, B. P., Soehner, A. M., and Clark, D. B. (2015). Sleep and circadian contributions to adolescent alcohol use disorder. Alcohol (Fayetteville, N.Y.), 49(4), 377387. DOI:10.1016/j.alcohol.2014.06.010.

68. Hastings, M. H., Reddy, A. B. and Maywood, E. S. (2003). A Clockwork Web: Circadian Timing in Brain and Periphery, in Health and Disease. Nature Reviews Neuroscience, 4(8), 649-661. DOI:10.1038/nrn1177.

69. Hilton, M. F., Chappell, M. J., Bartlett, W. A., Malhotra, A., Beattie, J. M. and Cayton, R. M. (2001). The Sleep Apnoea/Hypopnoea Syndrome Depresses Waking Vagal Tone Independent of Sympathetic Activation. The European Respiratory Journal, 17(6), 1258-1266. DOI:10.1 183/09031936.01.00009301.

70. Hummer, D. L., and Lee, T. M. (2016). Daily timing of the adolescent sleep phase: Insights from a crossspecies comparison. Neuroscience and Biobehavioral Reviews, 70, 171-181. DOI:10.1016/j.neubiorev.201 6.07.023.

71. Hysing, M., Pallesen, S., Stormark, K. M., Jakobsen, R., Lundervold, A. J., and Sivertsen, B. (2015). Sleep and use of electronic devices in adolescence: results from a large population-based study. BMJ open, 5(1), e006748. DOI:10.1136/bmjopen-2014-006748.

72. Jacob, B. A. and Rockoff, J. E. (2012). Organizing Schools to Improve Student Achievement: Start Times, Grade Configurations, and Teacher Assignments. Education Digest: Essential Readings Condensed for Quick Review, 77(8), 28-34. 
73. Jain, G. N., and Khare, A. (2020). Disruption in daily eating-fasting and activity-rest cycles in Indian adolescents attending school. PLOS ONE, 15(1), e0227002. DOI:10.1371/journal.pone.0227002.

74. Jenni, O. G., Achermann, P. and Carskadon, M. A (2005). Homeostatic Sleep Regulation in Adolescents Sleep 28(11): 1446-1454. DOI:10.1093/sleep/28.11.1 446.

75. Jones, S. G. and Benca, R. M. (2015).Circadian disruption in psychiatric disorders. Sleep Med. Clin., 10(4), 481 -93. DOI:10.1016/j.jsmc.2015.07.004.

76. Kalmbach, D. A., Schneider, L. D., Cheung, J., Bertrand, S. J., Kariharan, T., Pack, A. I., and Gehrman, P. R. (2017). Genetic Basis of Chronotype in Humans: Insights From Three Landmark GWAS. Sleep, 40(2), zsw048. DOI:10.1093/sleep/zsw048.

77. Karan, M., Bai, S., Almeida, D. M., Irwin, M. R., McCreath, H., and Fuligni, A. J. (2021). Sleep-Wake Timings in Adolescence: Chronotype Development and Associations with Adjustment. Journal of Youth and Adolescence, DOI:10.1007/s10964-021-01407-1.

78. Kelley, P., and Lockley, S. W. (2013). Synchronizing education to healthy adolescent brain development: sleep and circadian rhythms. In annual meeting of the American Educational Research Association, San Francisco, 27, 163-178

79. Kelley, P., and Lee, C. (2014). Later School Start Times in Adolescence: Time for Change. Denver, CO. The Education Commission of the States.

80. Kerkhof, G. A. (1985). Inter-individual differences in the human circadian system: a review. Biological psychology, 20(2), 83-112. DOI:10.1016/0301-0511(85)90019-5.

81. Kirby, M., Maggi, S., and D'Angiulli, A. (2011). School Start Times and the Sleep-Wake Cycle of Adolescents. Educational Researcher, 40, 56-61. DOI:10.3102/00131 89X11402323.

82. Kling, C., and Landgraf, D. (2021). Chapter 8 - Circadian Clocks, Stress, and Psychiatric Disorders. In G. Fink (Ed.), Stress: Genetics, Epigenetics and Genomics, 95108. DOI:10.1016/B978-0-12-813156-5.00008-X.

83. Knutson, K. L., and Lauderdale, D. S. (2009). Sociodemographic and behavioral predictors of bed time and wake time among US adolescents aged 15 to 17 years. The Journal of pediatrics, 154(3), 426-430.e1. DOI:10.1016/ j.jpeds.2008.08.035.

84. Kokka, I., Mourikis, I., Nicolaides, N. C., Darviri, C., Chrousos, G. P., Kanaka-Gantenbein, C., and Bacopoulou, F. (2021). Exploring the Effects of Problematic Internet Use on Adolescent Sleep: A Systematic Review. International Journal of Environmental Research and Public Health, 18(2). DOI:10.3390/ijerph18020760

85. Kozlowska, K., Scher, S., and Helgeland, H. (2020). The Circadian Clock and Functional Somatic Symptoms. In Functional Somatic Symptoms in Children and Adolescents: A Stress-System Approach to Assessment and Treatment, 97-118. DOI:10.1007/978-3-030-46184-3_5.

86. Liu, X., Zhang, L., Wu, G., Yang, R., and Liang, Y. (2021). The longitudinal relationship between sleep problems and school burnout in adolescents: A crosslagged panel analysis. Journal of Adolescence, 88, 1424. DOI:10.1016/j.adolescence.2021.02.001.

87. Lockley, S. W., Cronin, J. W., Evans, E. E., Cade, B. E.,
Lee, C. J., Landrigan, C. P., Rothschild, J. M., (2004). Effect of Reducing Interns' Weekly Work Hours on Sleep and Attentional Failures. The New England Journal of Medicine, 351 (18), 1829-1837. DOI:10.1056/NEJMoa 041404

88. Lockley, S. W., and Foster, R. G. (2012). Sleep: A Very Short Introduction. Oxford University Press. DOI:10.1093/actrade/9780199587858.001.0001

89. Lowden, A., Anund, A., Kecklund, G., Peters, B., and Akerstedt, T. (2009). Wakefulness in young and elderly subjects driving at night in a car simulator. Accident; analysis and prevention, 41(5), 1001-1007. DOI:10.10 16/j.aap.2009.05.014.

90. Bryant L, A., and Wolfson, A. R. (2010). Understanding adolescent caffeine use: connecting use patterns with expectancies, reasons, and sleep. Health education and behavior : the official publication of the Society for Public Health Education 37 (3), 330-342. DOI:10.1177/10901 98109341783.

91. Lund, H. G., Reider, B. D., Whiting, A. B., and Prichard, J. R. (2010). Sleep patterns and predictors of disturbed sleep in a large population of college students. The Journal of Adolescent Health : official publication of the Society for Adolescent Medicine, 46(2), 124-132. DOI:10.1016/j.jadohealth.2009.06.016.

92. Luyster, F. S., Strollo, P. J., Jr, Zee, P. C., Walsh, J. K., and Boards of Directors of the American Academy of Sleep Medicine and the Sleep Research Society. (2012). Sleep: a health imperative. Sleep, 35(6): 727-734. DOI:10.5665/sleep.1846.

93. Martino, T. A., Oudit, G. Y., Herzenberg, A. M., Tata, N., Koletar, M. M., Kabir, G. M., Belsham, D. D., Backx, P. H., Ralph, M. R., and Sole, M. J. (2008). Circadian rhythm disorganization produces profound cardiovascular and renal disease in hamsters. American Journal of Physiology. Regulatory, Integrative and Comparative Physiology, 294(5), R1675-R1683. DOI:10.1152/ ajpregu.00829.2007.

94. Matchock, R. L. and Mordkoff, J. T. (2009). Chronotype and Time-of-Day Influences on the Alerting, Orienting, and Executive Components of Attention. Experimental Brain Research, 192(2), 189-198. DOI:10.1007/s00221008-1567-6

95. McKay, S.L., Fouladirad, S. and Cameron, C.A. (2021). The Frustration Social Stressor for Adolescents (FSS A): A newly adapted psychosocial stressor. Stress and Health, DOI:10.1002/smi.3029.

96. Meltzoff, A. N., Kuhl, P. K., Movellan, J. and Sejnowski, T. J. (2009). Foundations for a New Science of Learning. Science, 325(5938), 284-288. DOI:10.1126/science. 1175626.

97. Miller, M. A., Kruisbrink, M., Wallace, J., Ji, C., and Cappuccio, F. P. (2018). Sleep duration and incidence of obesity in infants, children, and adolescents: a systematic review and meta-analysis of prospective studies. Sleep, 41(4), 10.1093/sleep/zsy018. DOI:10.1093/ sleep/zsy018.

98. Mohd Azmi, N., Juliana, N., Mohd Fahmi Teng, N. I., Azmani, S., Das, S., and Effendy, N. (2020). Consequences of Circadian Disruption in Shift Workers on Chrononutrition and their Psychosocial WellBeing. International Journal of Environmental Research 
and Public Health, 17(6), 2043. DOI:10.3390/ ijerph17062043.

99. Möller-Levet, C. S., Archer, S. N., Bucca, G., Laing, E. E., Slak, A., Kabiljo, R., Lo, J. C., et al. (2013). Effects of Insufficient Sleep on Circadian Rhythmicity and Expression Amplitude of the Human Blood Transcriptome. Proceedings of the National Society of Sciences of the United States of America, 110(12): E1132-E1141. DOI:10.1073/pnas.1217154110.

100.NCCIH. (2018). Energy drinks. National Center for Complementary and Integrative Health. https:// nccih.nih. gov/health/energy-drinks

101.NSF. (2006) Teens and Sleep. National Sleep Foundation: Sleep In America Polls. DOI:10.1016/j.sle h.2015.04.005

102.Norell-Clarke, A., and Hagquist, C. (2018). Child and adolescent sleep duration recommendations in relation to psychological and somatic complaints based on data between 1985 and 2013 from 11 to 15 yearolds. Journal of Adolescence, 68, 12-21. DOI:10.1016/ j.adolescence.2018.07.006.

103.O'Brien, E. M., and Mindell, J. A. (2005). Sleep and risk -taking behavior in adolescents. Behavioral Sleep Medicine, 3(3), 113-133. DOI:10.1207/ s15402010bsm0303_1.

104. Oike, H. (2017). Modulation of circadian clocks by nutrients and food factors. Bioscience, Biotechnology, and Biochemistry, 81(5), 863-870. DOI:10.1080/091684 51.2017.1281722.

105. Oyegbile, T. (2020). Defining, Assessing, and Treating Adolescent Insomnia and Related Sleep Problems Including Circadian Rhythm Disorders. In: Attarian H., Viola-Saltzman M. (eds) Sleep Disorders in Women. Current Clinical Neurology. Humana, Cham. DOI:10.1007/978-3-030-40842-8_8.

106.Pack, A. I., Pack, A. M., Rodgman, E., Cucchiara, A., Dinges, D. F., and Schwab, C. W. (1995). Characteristics of crashes attributed to the driver having fallen asleep. Accident; Analysis and Prevention 27 (6), 769 775. DOI:10.1016/0001-4575(95)00034-8

107.Pasch, K. E., Laska, M. N., Lytle, L. A., and Moe, S. G. (2010). Adolescent sleep, risk behaviors, and depressive symptoms: are they linked?. American Journal of Health Behavior, 34(2), 237-248. DOI:10.5993/aj hb.34.2.11.

108.Patte, K. A., Qian, W., and Leatherdale, S. T. (2017). Sleep duration trends and trajectories among youth in the COMPASS study. Sleep Health 3 (5), 309316. DOI:10.1016/j.sleh.2017.06.006

109.Peterson C. C. (1996). The ticking of the social clock: adults' beliefs about the timing of transition events. International Journal of Aging and Human Development, 42(3), 189-203. DOI: 10.2190/MMDD-F9YP -NPN8-720M.

110.Philip, P., Taillard, J., Léger, D., Diefenbach, K., Akerstedt, T., Bioulac, B., and Guilleminault, C. (2002). Work and rest sleep schedules of 227 European truck drivers. Sleep Medicine, 3(6), 507-511. DOI:10.1016/ s1389-9457(02)00138-7.

111.Pieters, S., Van Der Vorst, H., Burk, W. J., Wiers, R. W., and Engels, R. C. (2010). Puberty-dependent sleep regulation and alcohol use in early adoles- cents. Alcoholism, Clinical and Experimental Research, 34(9), 1512-1518. DOI:10.1111/j.1530-0277.2010.01 235.x.

112.Pizza, F., Contardi, S., Antognini, A. B., Zagoraiou, M., Borrotti, M., Mostacci, B., Mondini, S., and Cirignotta, F. (2010). Sleep quality and motor vehicle crashes in adolescents. Journal of clinical sleep medicine : JCSM : official publication of the American Academy of Sleep Medicine, 6(1): 41-45. DOI:10.5664/jcsm.27708.

113.Putwain, Dave. (2008). Examination stress and test anxiety. Psychologist 21, 1026-1029.

114.Randler C. (2011). Age and gender differences in morningness-eveningness during adolescence. The Journal of Genetic Psychology, 172(3), 302-308. DOI:10.1080/00221325.2010.535225.

115.Randler, C., Wolfgang, L., Matt, K., Demirhan, E., Horzum, M. B., and Beşoluk, Ş. (2016). Smartphone addiction proneness in relation to sleep and morningnesseveningness in German adolescents. Journal of Behavioral Addictions 5(3), 465-473. DOI:10.1556/2006.5.201 6.056.

116. Randler, C., FaßI, C., and Kalb, N. (2017). From Lark to Owl: developmental changes in morningnesseveningness from new-borns to early adulthood. Scientific Reports, 7, 45874. DOI:10.1038/ srep45874.

117.Rani, J. J. (2017). Academic Stress among School Students Writing Board Exam. International Journal of Advance Research, Ideas and Innovations in Technology, 2 (1). www.IJARnD.com.

118.Roehrs, T., and Roth, T. (2008). Caffeine: sleep and day-time sleepiness. Sleep Medicine Reviews, 12(2), 153-162. DOI:10.1016/j.smrv.2007.07.004.

119.Roenneberg, T., Kuehnle, T., Pramstaller, P. P., Ricken, J., Havel, M., Guth, A., and Merrow, M. (2004). A marker for the end of adolescence. Current Biology : CB, 14 (24), R1038-R1039. DOI:10.1016/j.cub.20 04.11.039.

120.Roenneberg, T. (2015). Having Trouble Typing? What on Earth Is Chronotype? Journal of Biological Rhythms, 30(6), 487-491. DOI:10.1177/0748730415603835.

121.Roenneberg, T., Kuehnle, T., Juda, M., Kantermann, T., Allebrandt, K., Gordijn, M. and Merrow, M. (2007). Epidemiology of the Human Circadian Clock. Sleep Medicine Reviews, 11(6), 429-438.

122.Rüger, M., St Hilaire, M. A., Brainard, G. C., Khalsa, S. B., Kronauer, R. E., Czeisler, C. A. and Lockley, S. W. (2012). Human Phase Response Curve to a Single $6.5 \mathrm{~h}$ Pulse of Short-Wavelength Light. The Journal of Physiology, 591(1), 353-363. DOI:10.1113/jphysiol.20 12.239046 .

123.Sagaspe, P., Taillard, J., Chaumet, G., Guilleminault, C., Coste, O., Moore, N., Bioulac, B., and Philip, P. (2007). Maintenance of wakefulness test as a predictor of driving performance in patients with untreated obstructive sleep apnea. Sleep, 30(3), 327-330.

124.Sakakibara, M., Kanematsu, T., Yasuma, F., and Hayano, J. (2008). Impact of real-world stress on cardiorespiratory resting function during sleep in daily life. Psychophysiology, 45(4), 667-670. DOI:10.1111/j.1469 -8986.2008.00665.x.

125.Sari, D. H. A., and Annisa, N. (2021). The Relationship 
Verma, P. et al. / J. Appl. \& Nat. Sci. 13(1): 327 - 342 (2021)

of Sleep Hygiene With Quality of Sleep in Adolescents. Proceedings of the 1st International Conference on Sport Sciences, Health and Tourism (ICSSHT 2019), 309-312. DOI:10.2991/ahsr.k.210130.066.

126.Sato, T., Ida, T., Kojima, M. (2017). Role of biological rhythms in the performance of physical activity. The Journal of Physical Fitness and Sports Medicine, 6(3), 125-34. DOI:10.7600/jpfsm.6.125.

127.Sawyer, S. M., Afifi, R. A., Bearinger, L. H., Blakemore, S. J., Dick, B., Ezeh, A. C. and Patton. G. C. (2012). Adolescence: A Foundation for Future Health. The Lancet, 379(9826), 1630-1640. DOI:10.1016/S014 0-6736(12)60072-5.

128.Saxvig, I. W., Pallesen, S., Wilhelmsen-Langeland, A., Molde, H., and Bjorvatn, B. (2012). Prevalence and correlates of delayed sleep phase in high school students. Sleep medicine, 13(2), 193-199. DOI:10.1016/ j.sleep.2011.10.024.

129.Schernhammer, E. S., Laden, F., Speizer, F. E., Willett, W. C., Hunter, D. J., Kawachi, I., Fuchs, C. S., and Colditz, G. A. (2003). Night-shift work and risk of colorectal cancer in the nurses' health study. Journal of the National Cancer Institute, 95(11), 825-828. DOI:10.1093/ jnci/95.11.825

130.Schmidt, C., Collette, F., Cajochen, C. and Peigneux, P. (2009). A Time to Think: circadian Rhythms in Human Cognition. Actas Españolas de Psiquiatría, 37(2), 68-74. DOI:10.1080/02643290701754158.

131.Scott, H., Biello, S. M., and Woods, H. C. (2019). Social media use and adolescent sleep patterns: crosssectional findings from the UK millennium cohort study. BMJ open, 9(9): e031161. DOI:10.1136/bmjopen2019-031161.

132.Shochat, T., Cohen-Zion, M., and Tzischinsky, O. (2014). Functional consequences of inadequate sleep in adolescents: a systematic review. Sleep Medicine Reviews, 18(1), 75-87. DOI:10.1016/j.smrv.2013.03.005.

133.Short, M. A., Weber, N., Reynolds, C., Coussens, S., and Carskadon, M. A. (2018). Estimating adolescent sleep need using dose-response modeling. Sleep, 41 (4): 10.1093/sleep/zsy011. DOI:10.1093/sleep/zsy011.

134.Sluggett, L., Wagner, S. L., and Harris, R. L. (2019). Sleep Duration and Obesity in Children and Adolescents. Canadian Journal of Diabetes, 43(2), 146-152. DOI:10.1016/j.jcjd.2018.06.006.

135.Smith-Coggins, R., Howard, S. K., Mac, D. T., Wang, C., Kwan, S., Rosekind, M. R., Sowb, Y., Balise, R., Levis, J., and Gaba, D. M. (2006). Improving alertness and performance in emergency department physicians and nurses: the use of planned naps. Annals of emergency medicine, 48(5), 596-604.e6043. DOI:10.1016/ j.annemergmed.2006.02.005.

136.Sørensen, K., Van den Broucke, S., Fullam, J., Doyle, G., Pelikan, J., Slonska, Z., Brand, H., and (HLS-EU) Consortium Health Literacy Project European (2012). Health literacy and public health: a systematic review and integration of definitions and models. BMC public health, 12, 80. DOI:10.1186/1471-2458-12-80.

137.Spear L. P. (2000). The adolescent brain and agerelated behavioral manifestations. Neuroscience and Biobehavioral Reviews, 24(4), 417-463. DOI:10.1016/ s0149-7634(00)00014-2.
138.Steven Reinberg (2016). Health Day Reporter. https:// www.webmd.com/sleep-disorders/news/20161109/ smartphones-may-hinder-a-good-nights-sleep

139.Stickgold, R., James, L. and Hobson, J. (2000). Visual discrimination learning requires sleep after training. Nat Neurosci 3: 1237-1238. DOI:10.1038/81756.

140.Stolarski, M., Gorgol, J., and Matthews, G. (2021). The search for causality of personality-chronotype associations: insights from a one-year longitudinal study of adolescents. Chronobiology International, 0(0), 1-12. DOI:10.1080/07420528.2020.1867157.

141.Susman, E. J., Dorn, L. D., and Schiefelbein, V. L. (2003). Puberty, sexuality, and Health. In R. M. Lerner, M. A. Easterbrooks, and J. Mistry (Eds.), Handbook of Psychology: Developmental Psychology, 6, 295-324. DOI:10.1002/0471264385.wei0612.

142. Tahara, Y., and Shibata, S. (2013). Chronobiology and nutrition. Neuroscience, 253, 78-88. DOI:10.1016/ j.neuroscience.2013.08.049.

143. Tamura, E. K., Oliveira-Silva, K. S., Ferreira-Moraes, F. A., Marinho, E. A. V, and Guerrero-Vargas, N. N. (2021). Circadian rhythms and substance use disorders: A bidirectional relationship. Pharmacology Biochemistry and Behavior, 201, 173105. DOI:10.1016/j.pbb.20 21.173105

144.Taylor, Daniel and Bramoweth, Adam. (2010). Patterns and Consequences of Inadequate Sleep in College Students: Substance Use and Motor Vehicle Accidents. The Journal of Adolescent Health : official publication of the Society for Adolescent Medicine, 46, 610-612. DOI:10.1016/j.jadohealth.2009.12.010.

145. Tonetti, L., Fabbri, M., and Natale, V. (2008). Sex difference in sleep-time preference and sleep need: a cross-sectional survey among Italian pre-adolescents, adolescents, and adults. Chronobiology International, 25(5), 745-759. DOI:10.1080/07420520802394191.

146.Tonetti, L., Adan, A., Caci, H., De Pascalis, V., Fabbri, M., and Natale, V. (2010). Morningness-eveningness preference and sensation seeking. European psychiatry: the Journal of the Association of European Psychiatrists, 25(2), 111-115. DOI:10.1016/j.eurpsy.2009.09.0 07.

147. Touitou, Y., and Point, S. (2020). Effects and mechanisms of action of light-emitting diodes on the human retina and internal clock. Environmental Research, 190, 109942. DOI:10.1016/j.envres.2020.109942.

148. Tsujino, N., and Sakurai, T. (2012). Nihon rinsho. Japanese Journal of clinical medicine, 70(7), 1121-1125.

149.Twenge, J. M., Krizan, Z., and Hisler, G. (2017). Decreases in self-reported sleep duration among U.S. adolescents 2009-2015 and association with new media screen time. Sleep Medicine, 39, 47-53. DOI:10.1016/ j.sleep.2017.08.013

150.Vernon, L., Modecki, K. L., and Barber, B. L. (2018). Mobile Phones in the Bedroom: Trajectories of Sleep Habits and Subsequent Adolescent Psychosocial Development. Child Development, 89(1), 66-77. DOI:10.111 $1 /$ cdev. 12836

151.Van Drunen, R., and Eckel-Mahan, K. (2021). Circadian Rhythms of the Hypothalamus: From Function to Physiology. Clocks and Sleep, 3(1), 189-226. DOI:10.3390/clockssleep3010012. 
152.Vorona, R. D., Szklo-Coxe, M., Wu, A., Dubik, M., Zhao, Y., and Ware, J. C. (2011). Dissimilar teen crash rates in two neighboring southeastern Virginia cities with different high school start times. Journal of clinical sleep medicine : JCSM : official publication of the American Academy of Sleep Medicine, 7 (2), 145-151.

153.Ward, E. (2021). Easing stress: Contract grading's impact on adolescents' perceptions of workload demands, time constraints, and challenge appraisal in high school English. Assessing Writing, 48, 100526. DOI:10.1016/ j.asw.2021.100526.

154.West, J., Carrell, S., and Shapiro, T. (2011). A's from Zzzz's? The Causal Effect of School Start Time on the Academic Achievement of Adolescents. American Economic Journal: Economic Policy, 3, 62-81. DOI:10.1257/ pol.3.3.62.

155.Wilhelm, I., Diekelmann, S., Molzow, I., Ayoub, A., Molle, M., and Born, J. (2011). Sleep Selectively Enhances Memory Expected to Be of Future Relevance. Journal of Neuroscience, 31(5), 1563-1569. DOI:1 0.1523/jneurosci.3575-10.2011.
156.Wittmann, M., Dinich, J., Merrow, M., and Roenneberg, T. (2006). Social jetlag: misalignment of biological and social time. Chronobiology international, 23(1-2), 497509. DOI:10.1080/07420520500545979.

157.Yasuma, N., Imamura, K., Watanabe, K., Nishi, D., Kawakami, N., and Takano, A. (2021). Association between energy drink consumption and substance use in adolescence: A systematic review of prospective cohort studies. Drug and Alcohol Dependence, 219, 108470. DOI:10.1016/j.drugalcdep.2020.108470.

158.Yvan Touitou, Sébastien Point. 2020. Effects and mechanisms of action of light-emitting diodes on the human retina and internal clock. Environmental Research, 190, 109942. DOI:10.1016/j.envres.2020.10 9942.

159.Zunhammer, M., Eberle, H., Eichhammer, P., and Busch, V. (2013). Somatic symptoms evoked by exam stress in university students: the role of alexithymia, neuroticism, anxiety and depression. PloS one, 8(12), e84911. DOI:10.1371/journal.pone.0084911. 